\title{
BMJ Open Quality Reducing neuroimaging in first-episode psychosis by facilitating uptake of choosing wisely recommendations: a quality improvement initiative
}

\author{
Raman Srivastava (D) , ${ }^{1} \mathrm{R}$ Davis Holmes (D) , ${ }^{2}$ Christopher W Noel (D) ,3,4 \\ Tong V Lam, ${ }^{5}$ Jason R Shewchuk ${ }^{2}$
}

To cite: Srivastava $\mathrm{R}$, Holmes RD, Noel CW, et al. Reducing neuroimaging in first-episode psychosis by facilitating uptake of choosing wisely recommendations: a quality improvement initiative. BMJ Open Quality 2021;10:e001307. doi:10.1136/ bmjoq-2020-001307

- Additional supplemental material is published online only. To view, please visit the journal online (http://dx.doi.org/10. 1136/bmjoq-2020-001307).

$\mathrm{RS}$ and RDH contributed equally.

Received 14 December 2020 Accepted 22 June 2021

\section{INTRODUCTION}

First-episode psychosis (FEP) is a frequent presentation to hospital. ${ }^{1}$ Neuroimaging is often ordered during the initial assessment to facilitate diagnostic buy-in, mitigate medico-legal concerns, and maximise assessment in a patient population that is typically marginalised. ${ }^{23}$ These benefits, however, are outweighed by the unnecessary radiation, cost, and strong evidence that neuroimaging rarely yields actionable findings. ${ }^{23}$ This stance is evidenced in international guidelines ${ }^{2}{ }^{3}$ and Choosing Wisely Canada (CWC) recommendations. ${ }^{4}$

Our site's radiology department queried inconsistent (per guidelines) CT imaging in FEP, given requisition patterns. We undertook a quality improvement initiative to determine the prevalence of inconsistent imaging and study the effectiveness of an intervention aimed at improving recommendation adherence.

\section{METHODS}

\section{Data collection}

All CT head studies with FEP-related indications performed at two local hospitals were identified through keyword searches of radiology reports containing any of the following terms: bizarre, delusion(s), delusional, hallucination(s), psychosis and psychotic. Extracted data included ordering physician specialty, provided indication, and imaging findings. Studies were classified as consistent or inconsistent with CWC guidelines. ${ }^{4}$ 'Later-age of onset', a CWC criterion for neuroimaging, is not defined by CWC and was chosen a priori to be age 40 years or more, based on local expert consensus and literature suggestions ranging from 35 to $50 .^{235-8}$ Chart review was used to clarify history and imaging indications when ambiguous requisition information was provided. All ambiguous cases were settled through consensus (RS and RDH).

Pre-intervention data collection was performed retrospectively from January to June 2018 (6 months). Although a 6-month post-audit period would have been sufficient based off a predetermined sample size calculation, we expanded the post-intervention period to 12 months to assess the durability of findings.

\section{Intervention}

Following collection of baseline pre-audit data, multidisciplinary stakeholders were consulted to develop study priorities, design, and interventions. Engaged stakeholders included local experts in quality improvement and psychosis, and administrators and support staff of psychiatry and radiology departments. Identified priorities were to minimise workflow disruption and studyspecific administrative burden. Stakeholder and literature evidence suggested the combination of audit and feedback with education, and separately visual prompts, could be successful in effecting change. ${ }^{9}$ From these considerations, we created a one-page infographic incorporating pre-intervention audit results and CWC guidelines (see online supplemental file 1), which was then emailed by department heads to high yield physician groups (emergency and psychiatry physicians) and physically posted throughout physician workspaces (walls and doors).

\section{Data analysis}

Basic descriptive and inferential statistics are reported. A Cochran-Mantel-Haenszel test was applied to a series of $2 \times 2$ contingency tables stratified by specialty, which compared consistent and inconsistent orders 
in the pre-audit and post-audit. The odds of ordering an inconsistent scan (outcome) in the post-intervention period (exposed group), relative to the pre-intervention period (reference) were estimated. Odds ratios (ORs) are reported with 95\% confidence intervals (CIs). All analysis was two-sided, and significance set at $\mathrm{p}<0.05$. Analysis was conducted on SAS Enterprise Guide V.7.1 and R Studio V.12.1.

\section{RESULTS}

\section{Patient and ordering physician characteristics}

Pre-intervention and post-intervention audits yielded 60 and $83 \mathrm{FEP}$ cases, respectively. The mean age for the entire cohort was 44 (standard deviation 18.6, range 17-100). Sixty-one $(43 \%)$ of patients were women. Psychiatrists and emergency physicians ordered the vast majority of CT scans during both pre-intervention $(97 \%)$ and postintervention $(92 \%)$ periods.

\section{Indications for head imaging and yield}

Among pre-intervention cases $(n=60)$, 'later-age of onset' was the most frequently cited valid indication $(n=22,37 \%)$ for head imaging. Other valid indications included 'other' $(\mathrm{n}=8,13 \%)$, 'headache' $(\mathrm{n}=5,8 \%)$, 'atypical psychosis features' $(n=4,7 \%)$, 'nausea or vomiting' $(n=2,3 \%)$, and 'seizure-like activity' $(\mathrm{n}=1,2 \%)$. A greater proportion of post-intervention cases were due to 'later-age of onset' $(\mathrm{n}=51,61 \%)$. Other valid indications post-intervention were 'atypical psychosis features' $(n=17,20 \%)$, 'query autoimmune encephalitis' ( $n=3,4 \%)$, 'headache' $(n=4$, $5 \%)$, 'seizure-like activity' $(\mathrm{n}=1,1 \%)$, 'nausea or vomiting' $(\mathrm{n}=1,1 \%)$, and 'other' $(\mathrm{n}=11,13 \%)$.

No structural cause for psychosis was identified in any CT study within this project.

\section{Intervention effectiveness}

There was a significant decrease in the proportion of inconsistent CT studies from $50 \%$ to $16 \%$ post-intervention (OR 0.2 ; $95 \%$ CI 0.09 to $0.44, \mathrm{p}<0.01)$. When the 12 -month postintervention period is divided into two 6-month blocks ('post1' and 'post2'), similar reductions are observed (17\% and $15 \%$, respectively). Figure 1 demonstrates the number of consistent and inconsistent scans in the pre-audit and postaudits, stratified by physician specialty.

\section{DISCUSSION}

An audit of CT usage in FEP was conducted at two local institutions before and after implementing an intervention of feedback, education, and visual prompting, which aimed to align ordering practices with guideline recommendations. Psychiatrists and emergency physicians were responsible for the majority of requests and were most directly targeted.

Our study suggests that infographics can be used to decrease CT scans inconsistent with CWC recommendations, in patients with FEP. Post intervention, the 6-month rate of inconsistent CT head requests decreased from $50 \%$ to $17 \%$ and $15 \%$ (at 6 months and 12 months, respectively). This outcome is highly relevant in healthcare, where a limited

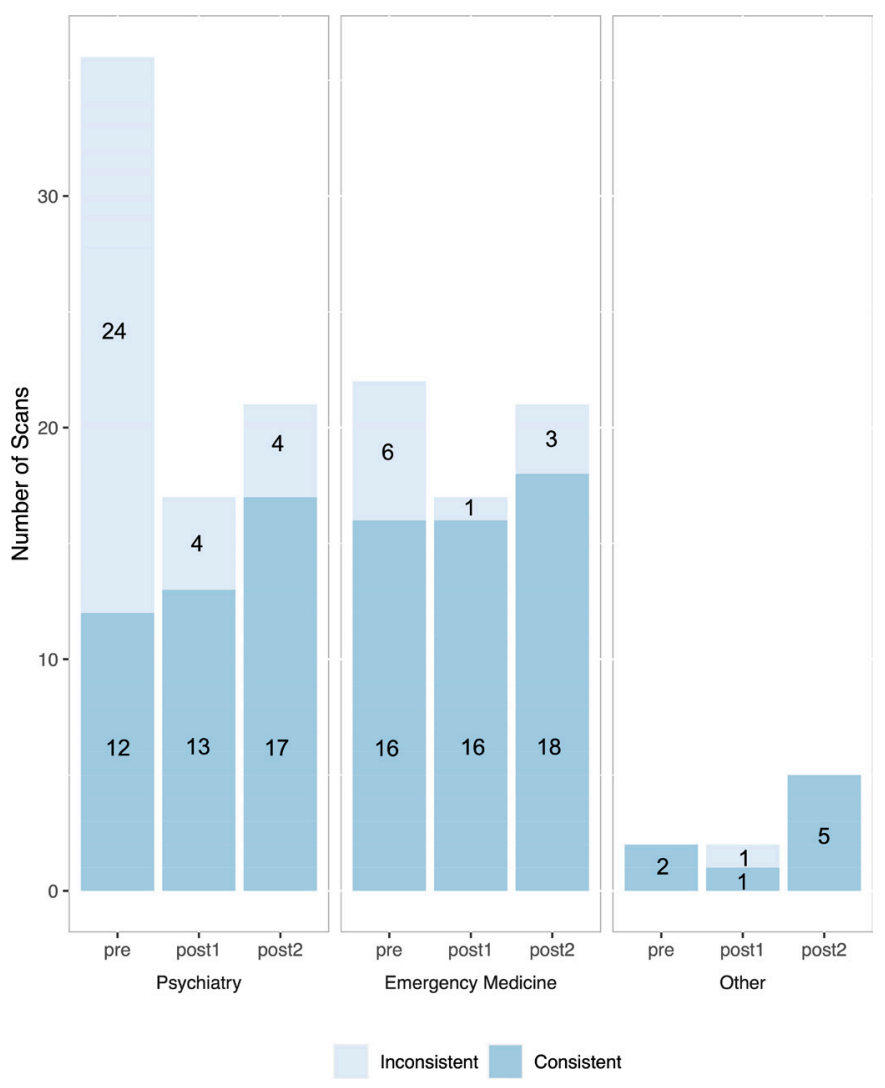

Figure 1 Summary of CT scans performed for first-episode psychosis during the pre-intervention (pre), first 6 months of post-intervention (post1), and second 6 months of postintervention (post2) periods, stratified by ordering physician specialty. Chart bars are divided according to consistency with Choosing Wisely Canada recommendations into either consistent (dark blue) or inconsistent (light blue) scans.

capacity to modify workflows is a near ubiquitous constraint. Although passive educational methods receive criticism for their ineffectiveness, ${ }^{10}$ a growing body of literature supports this and our other interventions. A recent study found that among reviewed initiatives with sustained results, each of our three strategies-audit and feedback, education, and reminders-were present. ${ }^{11}$ A 2017 systematic review found that provider education, performance feedback, and multicomponent interventions all have strong evidence for reducing low-value health services. ${ }^{12}$ Most recently, a similar education and feedback intervention was shown to durably reduce cardiac echocardiograms. ${ }^{13}$ Critical to our success was our team, multicomponent approach, and visual prompts. Engaging multidisciplinary stakeholders, including our target clinician groups, led to practical insights for optimising the intervention approach. Our intervention also likely benefited from synergistic effects associated with using several evidence-based approaches together, and clear and consistent reminders achieved with the physical placement of cues in the work environment.

The results of our initiative also lend further support to evidence-based guidelines ${ }^{3} 14^{15}$ indicating CT imaging for FEP provides minimal utility; no explanatory intracranial 
abnormality was identified during the pre-intervention or post-intervention audits.

Several limitations merit discussion. By prioritising minimal workflow disturbance over obtaining process measures, we cannot firmly establish a link between our intervention and results, nor could we run successive Plan Do Study Act (PDSA) cycles to optimise interventions. Calendar-year timing differences between audits may also impact results. Finally, while our preference would have been to display the data in a run chart format, ${ }^{16}$ our dichotomous outcome and insufficient number of observations precluded its usage.

\section{CONCLUSIONS}

1. Reducing guideline-inconsistent testing may be achieved through infographics employing minimallyinvasive feedback mechanisms (audit and feedback, education, and reminders) with visual prompts in physical spaces.

2. CT neuroimaging has a limited role in FEP and we recommend following CWC recommendations. Future studies should aim to identify a specific age with which to define the 'later-age of onset' criterion.

\section{Author affiliations}

${ }^{1}$ Department of Psychiatry, The University of British Columbia Faculty of Medicine, Vancouver, British Columbia, Canada

${ }^{2}$ Department of Radiology, The University of British Columbia Faculty of Medicine, Vancouver, British Columbia, Canada

${ }^{3}$ Department of Otolaryngology, University of Toronto Faculty of Medicine, Toronto, Ontario, Canada

${ }^{4}$ Institute of Health Policy Management and Evaluation, Dalla Lana School of Public Health, University of Toronto, Toronto, Ontario, Canada

${ }^{5}$ Department of Emergency Medicine, Vancouver General Hospital, Vancouver, British Columbia, Canada

Acknowledgements Dr Michael A Irvine from the Clinical Research Support Unit, BC Children's Hospital Research Institute for his assistance with statistical analysis approaches for the study.

Contributors RS, RDH, JS and TL designed and conducted the quality improvement project and performed the intervention. RS and RDH conducted data acquisition. RS, RDH and CN performed data analysis, data interpretation and manuscript preparation, with important intellectual input from TL and JS. All authors approve of the final version of this manuscript.

Funding The authors have not declared a specific grant for this research from any funding agency in the public, commercial or not-for-profit sectors.

Competing interests None declared.

Patient and public involvement statement Patients and members of the public were not involved in the performance of this quality initiative.

Patient consent for publication Not required.

Ethics approval The radiology department pursued this initiative for organisational quality improvement. Guidance from the University of British Columbia's Behavioral Research Ethics Board (IRB equivalent in Canada) deemed this type of initiative as falling under QI ethics exemption under Article 2.5 of the 2018 Tri-Council Policy Statement. Results are presented anonymously and in aggregate to minimise re-identification risk.

Provenance and peer review Not commissioned; externally peer reviewed.
Supplemental material This content has been supplied by the author(s). It has not been vetted by BMJ Publishing Group Limited (BMJ) and may not have been peer-reviewed. Any opinions or recommendations discussed are solely those of the author(s) and are not endorsed by BMJ. BMJ disclaims all liability and responsibility arising from any reliance placed on the content. Where the content includes any translated material, BMJ does not warrant the accuracy and reliability of the translations (including but not limited to local regulations, clinical guidelines, terminology, drug names and drug dosages), and is not responsible for any error and/or omissions arising from translation and adaptation or otherwise.

Open access This is an open access article distributed in accordance with the Creative Commons Attribution Non Commercial (CC BY-NC 4.0) license, which permits others to distribute, remix, adapt, build upon this work non-commercially, and license their derivative works on different terms, provided the original work is properly cited, appropriate credit is given, any changes made indicated, and the use is non-commercial. See: http://creativecommons.org/licenses/by-nc/4.0/.

ORCID iDs

Raman Srivastava http://orcid.org/0000-0003-1792-7868

R Davis Holmes http://orcid.org/0000-0002-9106-4979

Christopher W Noel http://orcid.org/0000-0002-6625-0809

\section{REFERENCES}

1 Perälä J, Suvisaari J, Saarni SI, et al. Lifetime prevalence of psychotic and bipolar I disorders in a general population. Arch Gen Psychiatry 2007;64:19-28.

2 Andrea S, Papirny M, Raedler T. Brain imaging in adolescents and young adults with First-Episode psychosis: a retrospective cohort study. J Clin Psychiatry 2019;80:18m12665.

3 Forbes M, Stefler D, Velakoulis D, et al. The clinical utility of structural neuroimaging in first-episode psychosis: a systematic review. Aust $N$ Z J Psychiatry 2019;53:1093-104.

4 Choosing Wisely Canada - Psychiatry. Available: https:// choosingwiselycanada.org/psychiatry/ [Accessed 11 Oct 2019].

5 Coentre R, Silva-Dos-Santos A, Talina MC. Retrospective study on structural neuroimaging in first-episode psychosis. PeerJ 2016;4:e2069.

6 Iglewicz A, Meeks TW, Jeste DV. New wine in old bottle: late-life psychosis. Psychiatr Clin North Am 2011;34:295-318.

7 Power BD, Nguyen T, Hayhow B, et al. Neuroimaging in psychiatry: an update on neuroimaging in the clinical setting. Australas Psychiatry 2016;24:157-63.

8 Guze $\mathrm{BH}$, James M. Medical assessment and laboratory testing in psychiatry. In: Sadock BJ, Sadock VA, Ruiz P, eds. Kaplan and Sadock's Comprehensive Textbook of Psychiatry. Philadelphia, United States: Wolters Kluwer Health, 2009: 995-1013.

9 Vratsistas-Curto A, McCluskey A, Schurr K. Use of audit, feedback and education increased guideline implementation in a multidisciplinary stroke unit. BMJ Open Qual 2017;6:e000212.

10 Soong C, Shojania KG. Education as a low-value improvement intervention: often necessary but rarely sufficient. BMJ Qual Saf 2020;29:353-7.

11 Kearsley-Ho EL, Yang HY, Karunananthan S, et al. When do trials of diabetes quality improvement strategies lead to sustained change in patient care? BMJ Qual Saf 2020;29:774-6.

12 Colla $\mathrm{CH}$, Mainor AJ, Hargreaves C, et al. Interventions aimed at reducing use of low-value health services: a systematic review. Med Care Res Rev 2017;74:507-50.

13 Bhatia RS, Ivers NM, Yin XC, et al. Improving the appropriate use of transthoracic echocardiography: the echo wisely trial. J Am Coll Cardiol 2017;70:1135-44.

14 Robert Williams S, Yukio Koyanagi C, Shigemi Hishinuma E. On the usefulness of structural brain imaging for young first episode inpatients with psychosis. Psychiatry Res 2014;224:104-6.

15 Agzarian MJ, Chryssidis S, Davies RP, et al. Use of routine computed tomography brain scanning of psychiatry patients. Australas Radiol 2006;50:27-8.

16 Perla RJ, Provost LP, Murray SK. The run chart: a simple analytical tool for learning from variation in healthcare processes. BMJ Qual Saf 2011;20:46-51. 